\title{
Optimization of FDM 3D Printing Process Parameter for Improving Porosity Accuracy of PLA Scaffold
}

\author{
Zainal Abidin ${ }^{1}$ M. Yanis ${ }^{1}$ M. Zahri Kadir ${ }^{1}$ Astuti ${ }^{1}$ Akbar Teguh Prakoso ${ }^{1}$ Edo \\ Syahrizal $^{1}$ Ardiyansyah Syahrom ${ }^{2,3}$ Hasan Basri ${ }^{1, *}$ \\ ${ }^{1}$ Department of Mechanical Engineering, Faculty of Engineering, Universitas Sriwijaya, Indralaya 30662, Ogan \\ Ilir, South Sumatera, Indonesia \\ ${ }^{2}$ Department of Applied Mechanics and Design, Faculty of Mechanical Engineering, Universiti Teknologi \\ Malaysia, Skudai 81310, Johor, Malaysia \\ ${ }^{3}$ Medical Device and Technology Center (Meditec), Institute of Human-Centered and Engineering (IHCE), \\ Universiti Teknologi Malaysia, Skudai 81310, Johor, Malaysia \\ * Corresponding author: Email: hasan_basri@unsri.ac.id
}

\begin{abstract}
This study aims to obtain optimal porosity results from bone scaffolding printing using FDM type 3D printing machines using PLA material. In this study, the bone scaffold was modeled using Solid Works. This research's main contribution is to obtain optimal settings in the molding of bone scaffolding using the Taguchi method. The Taguchi method is used based on its efficiency; this is because orthogonal arrays require fewer experiments than experimental designs. Analysis of variance is needed to see the factors that have a significant effect on the response variable. The results showed that the factors that significantly affected the bone scaffold's porosity quality were $42.22 \%$ nozzle temperature, $10.81 \%$ layer thickness, and $0.78 \%$ printing speed, respectively. The optimal operating parameter settings are at a nozzle temperature of $210^{\circ} \mathrm{C}$, a printing speed of $25 \mathrm{~mm} / \mathrm{s}$, and a layer thickness of $0.1 \mathrm{~mm}$, which are ideal settings for printing bone scaffolds so that porosity deviations can be minimized.
\end{abstract}

Keywords: bone scaffold, PLA, Taguchi Method, Density, microscope

\section{INTRODUCTION}

The combination of medical science and mechanical science currently developing is referred to as biomechanics - applications in this area, for example, in the bone. Bones have the unique feature of their ability to self-regenerate within a small scope of the damage. However, if there is more significant damage, then additional treatment is needed [1]. Tissue engineering methods have succeeded in increasing the ability to regenerate bone through bone scaffolds, which have been designed to promote the growth of new tissue in bone. This method has provided a well-preserved bone growth and repair system because the bone scaffold has been designed to use non-toxic materials and support bone tissue growth (biocompatibility). Besides, the bone scaffold is also designed to match the tissue. Original bone has a porous structure, so it can allow osteoconductivity, which can allow nutrients and boneforming cells (osteoblasts) to develop and stick in the pores [2].
Polylatic Acid (PLA) is often used in the medical field used as a suture material, for bone fixation and reconstruction, for drug delivery devices, manual nerve regeneration, and ligament reconstruction. Because it has excellent compatibility and bio-absorbability, it can be degraded in the human body [3]. PLA is a biodegradable plastic that comes from renewable sources like fermented plant starch, like corn, sweet potato, or sugar beet, making it a safe alternative [4]. Additive Manufacture (AM) is one of the most promising fields in component manufacturing. One of them is Fused Deposition Modeling (FDM), which allows solid parts that structured from thermoplastic polymers; the rigidity and strength are relatively small compared to other techniques. Apart from the particular study, the result from additive manufacturing in components with layered microstructure; in each layer, a 3D printed material's mechanical properties depend on the direction. Complex processing from many parameter affected the quality and material properties called FDM, these combination of parameters frequently hard to 
understand. Parameter printing like building orientation, raster angle, raster width, layer thickness, density, air gap, fill pattern, and feed rate, from others, have significant influence from performance, quality of FDM printed parts [5]. 3D printing machines are widely used because they make a good quality work-pieces using a low manufacturing costs, efficient times, more high productived levels, their print capability to directly make porous bone scaffolding with designed shapes, controlled chemistry, and interconnected porous. These inorganic bone scaffolds is biodegradable and ideal for bone tissue engineering, even with growth factors or specific-site drug delivery capabilities [6].

Bone is an open-cell, divided into two, namely, cancellous bone and compact bone. Compact bone has a tough outer shell with a low level of porosity, while cancellous bone has interconnecting bone cells that function to form a very porous structure that is softer and lighter than the bone's outer shell (compact bone). The porous structure can provide room for the development of new bone tissue and tissue circulation. Besides, the porous bone scaffold can also provide the support needed for cells to reproduce and maintain their original function, and until the development of new bone structures is formed during the growth process. Pore size is also an essential factor in bone scaffolding design. Porous size is significant factors determining mechanical strength and flow rate of bone scaffold. At different pore sizes, the porosity increases, and strength to hold compress energy decreases due to the increase in interconnection. Meanwhile, if porosity decreases, and strength to hold compress energy increases as the pore size increases due to the same bone scaffold interconnections [7].

This paper aims to determine the optimization of scaffold fabrication using $3 \mathrm{D}$ printing with PLA material. The Taguchi method was used in this study to determine the optimization of FDM 3D printing process parameter for improving porosity accuracy of PLA scaffold. This method was chosen because it was efficient and improved from research and development and high-quality products can produced more efficient in time and production cost. With a optimization of FDM 3D printing process parameter for improving porosity accuracy of PLA scaffold with a $49.93 \%$ porosity to get the value as expected, the parameter variation is carried out. For porosity analysis, density testing was performed and for observation using an optical microscope.

\section{MATERIALS AND METHOD}

\subsection{D-Model Preparation and Characterization}

Three-dimensional rectangular models are produced using computer-aided design (CAD) software with a 10 mm x 10 mm x 16.25 mm (see Figure 1). With $49.93 \%$ porosity, it was obtained porosity using Solidworks through the properties of the mass of the pore volume of $811.40 \mathrm{~mm}^{3}(49.93 \%)$ of the solid volume of $1625 \mathrm{~mm}^{3}$ $(100 \%)$ and the jig that was designed using SolidWorks adjusted to the size of the SHIMADZU AUX220 scales (see Figure 2).

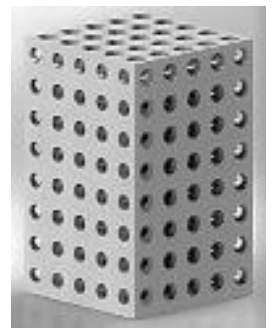

Figure 1 Porous bone scaffolding model

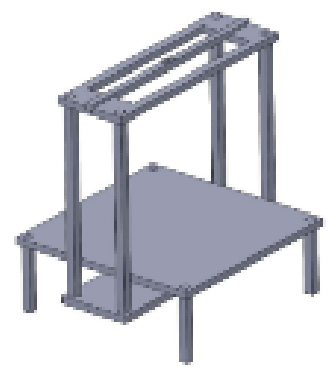

Figure 2 Jig Design

\subsection{Design of experiment}

The experiment's design are used in the literature several times for FDM to make a conclusion that process parameters such as raster angle, air gap, layer thickness, raster width, and slice height significantly influence viscoelastic and other material properties of ABS or PLA [8]. To achieve a solid design in the scaffold fabrication process, the Taguchi method is used because it is more structured and efficient. In this work, the Taguchi method is used to obtain the minimum PLA distortion conditions. The parameters selected are temperature, printing speed, and layer thickness, which can be seen in Table 1 . 


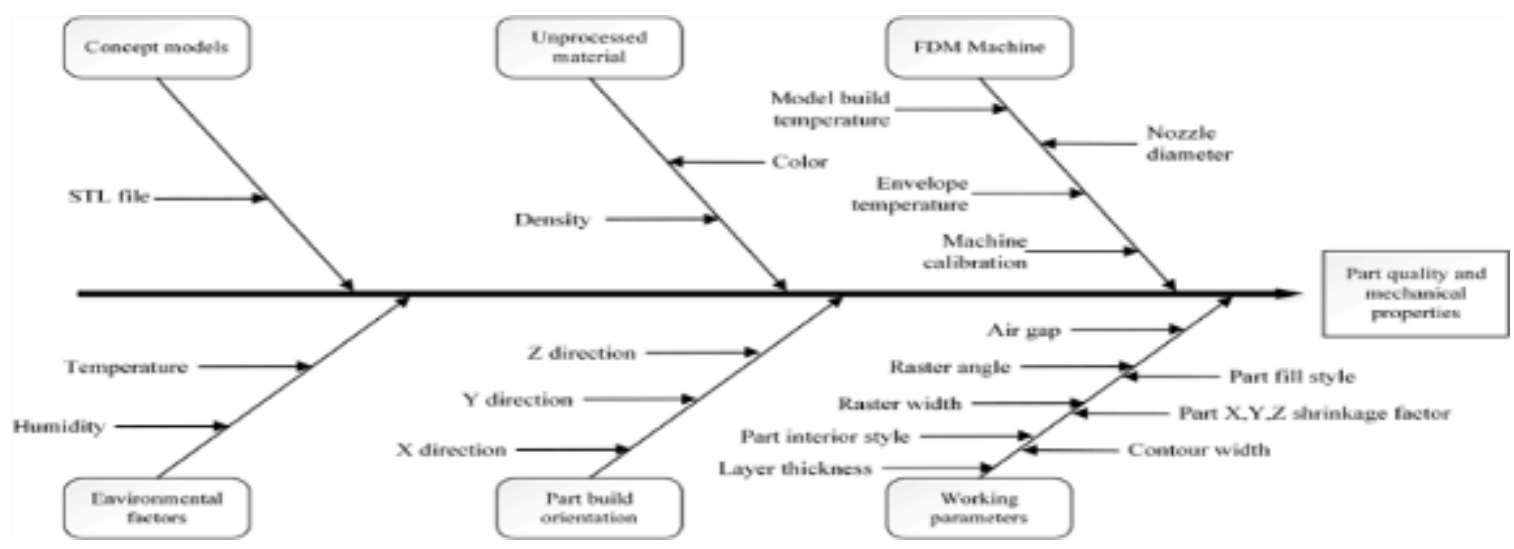

Figure 3. Diagram effect of FDM process parameters [8].

Table 1. Variables and Variations

\begin{tabular}{l|c|c|c}
\hline \multirow{2}{*}{ Factor } & \multicolumn{3}{c}{ Level } \\
\cline { 2 - 4 } & $\mathbf{1}$ & $\mathbf{2}$ & $\mathbf{3}$ \\
\hline Temperature $(\mathrm{A})$ & $200^{\circ} \mathrm{C}$ & $210^{\circ} \mathrm{C}$ & $215^{\circ} \mathrm{C}$ \\
\hline Printing Speed $(\mathrm{B})$ & $20 \mathrm{~mm} / \mathrm{s}$ & $25 \mathrm{~mm} / \mathrm{s}$ & $30 \mathrm{~mm} / \mathrm{s}$ \\
\hline Layer Thickness $(\mathrm{C})$ & $0.0875 \mathrm{~mm}$ & $0.1 \mathrm{~mm}$ & 0.1125 \\
\hline
\end{tabular}

Table 2. Taguchi L9 orthogonal array

\begin{tabular}{c|c|c|c|c|c|c}
\hline $\begin{array}{c}\text { Experiment } \\
\text { Number }\end{array}$ & \multicolumn{3}{|c|}{ Factor } & \multicolumn{4}{c}{ Experimental Value } \\
\cline { 2 - 7 } & A & $\boldsymbol{B}$ & $\boldsymbol{C}$ & Temperature & Printing Speed & Layer Thickness \\
\hline 1 & 1 & 1 & 1 & $200^{\circ} \mathrm{C}$ & $20 \mathrm{~mm} / \mathrm{s}$ & $0.0875 \mathrm{~mm}$ \\
\hline 2 & 1 & 2 & 2 & $200^{\circ} \mathrm{C}$ & $25 \mathrm{~mm} / \mathrm{s}$ & $0.1 \mathrm{~mm}$ \\
\hline 3 & 1 & 3 & 3 & $200^{\circ} \mathrm{C}$ & $30 \mathrm{~mm} / \mathrm{s}$ & $0.1125 \mathrm{~mm}$ \\
\hline 4 & 2 & 1 & 2 & $210^{\circ} \mathrm{C}$ & $20 \mathrm{~mm} / \mathrm{s}$ & $0.1 \mathrm{~mm}$ \\
\hline 5 & 2 & 2 & 3 & $210^{\circ} \mathrm{C}$ & $25 \mathrm{~mm} / \mathrm{s}$ & $0.1125 \mathrm{~mm}$ \\
\hline 6 & 2 & 3 & 1 & $210^{\circ} \mathrm{C}$ & $30 \mathrm{~mm} / \mathrm{s}$ & $0.0875 \mathrm{~mm}$ \\
\hline 7 & 3 & 1 & 3 & $215^{\circ} \mathrm{C}$ & $20 \mathrm{~mm} / \mathrm{s}$ & $0.1125 \mathrm{~mm}$ \\
\hline 8 & 3 & 2 & 1 & $215^{\circ} \mathrm{C}$ & $25 \mathrm{~mm} / \mathrm{s}$ & $0.0875 \mathrm{~mm}$ \\
\hline 9 & 3 & 3 & 2 & $215^{\circ} \mathrm{C}$ & $30 \mathrm{~mm} / \mathrm{s}$ & $0.1 \mathrm{~mm}$ \\
\hline
\end{tabular}

The L9 orthogonal array Taguchi method is suitable for three factors with three levels, as shown in Table 2. The data obtained comes from existing research studies, which are then processed to analyze the bone scaffold's quality. Determination of the quality of the bone scaffold using the main variables (variable factors), namely temperature, printing speed, and layer thickness.

\section{RESULTS AND DISCUSSION}

Figure 3 is a scaffold that has been printed. In the testing process, it is done by measuring the dry mass of each specimen and measuring the wet mass of each specimen. For wet mass weighing, it is done by hanging on a jig that has been designed using Solid Works adjusting to the size of the SHIMADZU AUX220 scales and printed using $3 \mathrm{D}$ printing then the specimen is hung with the rope that is supported by the jig and the specimen is weighed in a measuring cup containing ethanol without touching the bottom of the measuring cup, which is in the middle of the measuring cup as in Figure 4 and Figure 5. 


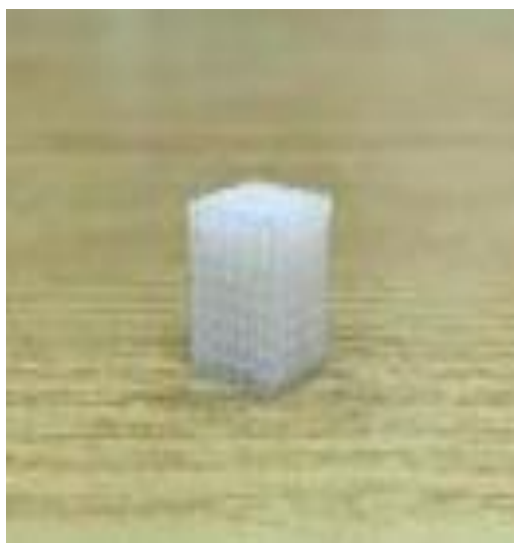

Figure 4 Printed scaffold

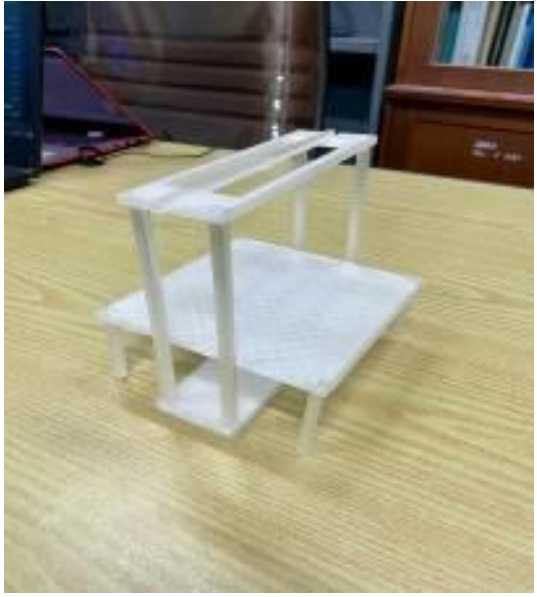

Figure 5. Printed Jig

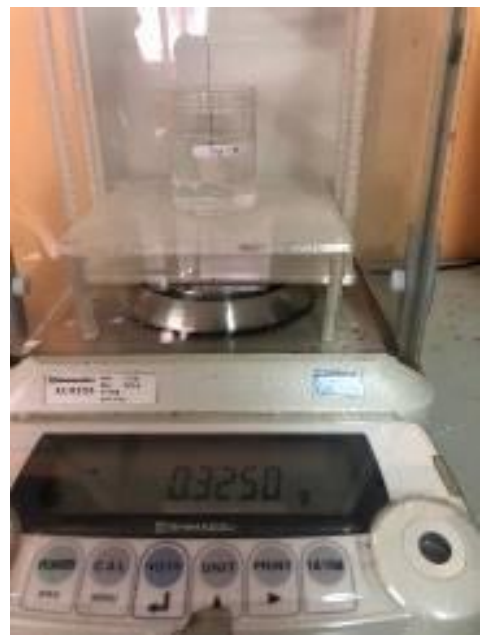

Figure 6 The jig is attached to the scale

In taking scaffold data with a porosity target of $49.93 \%$, the specimen measurement was obtained from the calculation using Archimedes' law [9]. Knowing the PLA and the density of ethanol can be calculated from the pore volume from the dry scaffold mass (Md) and the wet mass $(\mathrm{Mw})$. The mass of the swollen scaffolding is determined by putting it in ethanol. Mass of ethanol in open pores.

(M pore) using equation (1), a determined scaffold is,

$M_{\text {pore }}=M_{W}-M_{d}$

With consistency of ethanol ( $\rho$ _ethanol: $0,7811 \mathrm{~g} / \mathrm{cm} 3$ ), from equation (2) calculated pore volume are,

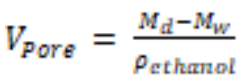

The scaffold volume is calculated using PLA density $\left(\rho_{P L A}: 1.17 \mathrm{~g} / \mathrm{cm} 3\right)$ with Equation (3),

$V_{\text {skafold }}=\frac{M_{\text {di }}}{p_{\text {PLA }}}$

Porous $(\mathrm{P})$ is determined with equation (4),

Porosity $=\frac{V_{\text {pors }}}{V_{\text {pors }}+V_{\text {shafold }}}$

Table 3 shows results from tested porosity. Analysis of variance (ANOVA) is used to identify factors that contribute significantly to the porosity target. Table 4 shows average porosity and $\mathrm{S} / \mathrm{N}$ ratio. To achieve the target value of $49.93 \%$, 
Table 3. Porosity values for all specimens

\begin{tabular}{|c|c|c|c|c|c|c|}
\hline \multirow{3}{*}{ No } & & Factor & & & Replications & \\
\hline & Temperature & Printing Speed & $\begin{array}{l}\text { Layer } \\
\text { Thickness }\end{array}$ & $\begin{array}{c}\text { Porosity } \\
(\%)\end{array}$ & $\begin{array}{c}\text { Porosity } \\
(\%)\end{array}$ & $\begin{array}{c}\text { Porosity } \\
(\%)\end{array}$ \\
\hline & $\left({ }^{\circ} \mathrm{C}\right)$ & $(\mathrm{mm} / \mathrm{s})$ & $(\mathbf{m m})$ & & & \\
\hline 1 & 200 & 20 & 0.0875 & 50.43 & 49.27 & 50.10 \\
\hline 2 & 200 & 25 & 0.1 & 50.33 & 50.13 & 50.30 \\
\hline 3 & 200 & 30 & 0.1125 & 50.09 & 49.22 & 49.32 \\
\hline 4 & 210 & 20 & 0.1 & 49.39 & 49.49 & 49.54 \\
\hline 5 & 210 & 25 & 0.1125 & 49.74 & 49.64 & 48.98 \\
\hline 6 & 210 & 30 & 0.0875 & 49.71 & 49.45 & 49.72 \\
\hline 7 & 215 & 20 & 0.1125 & 49.45 & 50.44 & 50.06 \\
\hline 8 & 215 & 25 & 0.0875 & 50.31 & 50.44 & 50.68 \\
\hline 9 & 215 & 30 & 0.1 & 50.53 & 50.45 & 50.80 \\
\hline
\end{tabular}

\begin{tabular}{|c|c|c|c|c|c|c|}
\hline \multirow{2}{*}{$\begin{array}{l}\text { Experiment } \\
\text { Number }\end{array}$} & \multicolumn{3}{|c|}{ Controlled Factors } & \multirow{2}{*}{$\begin{array}{c}\text { Mean } \\
(\%)\end{array}$} & \multirow{2}{*}{$\begin{array}{l}\text { Standar } \\
\text { deviation }\end{array}$} & \multirow{2}{*}{ S/N Ratio } \\
\hline & $\boldsymbol{A}$ & $\boldsymbol{B}$ & $C$ & & & \\
\hline 1 & 1 & 1 & 1 & 49.93 & 0.60 & 38.4685 \\
\hline 2 & 1 & 2 & 2 & 50.26 & 0.11 & 53.5478 \\
\hline 3 & 1 & 3 & 3 & 49.55 & 0.48 & 40.2986 \\
\hline 4 & 2 & 1 & 2 & 49.47 & 0.07 & 56.8214 \\
\hline 5 & 2 & 2 & 3 & 49.45 & 0.41 & 41.5600 \\
\hline 6 & 2 & 3 & 1 & 49.63 & 0.15 & 50.2881 \\
\hline 7 & 3 & 1 & 3 & 49.99 & 0.50 & 40.0492 \\
\hline 8 & 3 & 2 & 1 & 50.48 & 0.19 & 48.6234 \\
\hline 9 & 3 & 3 & 2 & 50.59 & 0.18 & 48.8476 \\
\hline
\end{tabular}

Table 4. Mean porosity and S / N ratio

; A2 and C2, while factor B or printing speed is less

Table 5. The average porosity value

\begin{tabular}{c|c|c|c}
\hline \multirow{2}{*}{ Level } & \multicolumn{3}{|c}{ Factor } \\
\cline { 2 - 4 } & A & B & C \\
\hline Level 1 & 49.91 & 49.80 & 50.01 \\
\hline Level 2 & 49.52 & 50.06 & 50.11 \\
\hline & & & \\
\hline Level 3 & 50.35 & 49.92 & 49.66 \\
\hline Difference & 0.83 & 0.26 & 0.44 \\
\hline Rank & 1 & 3 & 2 \\
\hline
\end{tabular}

"Nominal to Better" is used. Table 5 and Table 6 , to get the best level, the level that produces the highest average value of $\mathrm{S} / \mathrm{N}$ ratio among others will be selected. The most considerable $\mathrm{S} / \mathrm{N}$ ratio value was chosen because it is more robust against the noise factor [10]. Figure 7 and Figure 8 show a graph of the mean hardness response for each factor. The optimal hardness value condition is achieved based on the condition influential because the F-ratio is lower than the $\mathrm{F}$ distribution $(0.05)(2.18)=3.55$ with a significant level $\alpha=005$

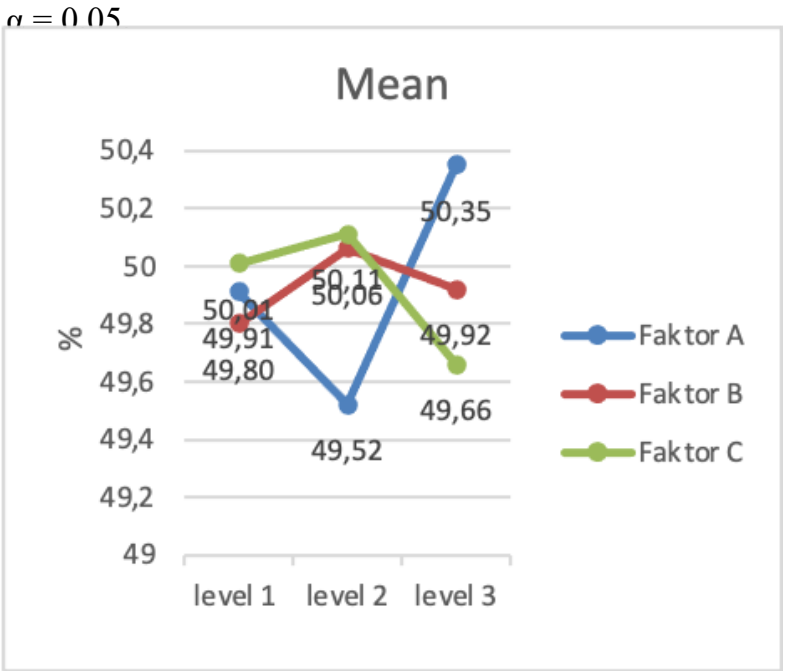

Figure 7. Average porosity graph 
Table 6. The average porosity value

\begin{tabular}{c|c|c|c}
\multirow{2}{*}{ Level } & \multicolumn{3}{|c}{ Factor } \\
\cline { 2 - 4 } & $\mathbf{A}$ & $\mathbf{B}$ & $\mathbf{C}$ \\
\hline Level 1 & 44.10 & 45.11 & 45.79 \\
\hline Level 2 & 49.56 & 47.91 & 53.07 \\
\hline Level 3 & 45.84 & 46.48 & 40.63 \\
\hline Difference & 5.45 & 2.79 & 12.44 \\
\hline Rank & 2 & 3 & 1 \\
\hline
\end{tabular}

Based on the ANOVA results, as shown in Table 7. It is known that Factor $\mathrm{A}$ and Factor $\mathrm{C}$ increase the porosity where factor A makes a $42.22 \%$ contribution and factor B $10.81 \%$. Factor B has less effect on scaffold porosity because it gets 0.784 which is below $\mathrm{F}$ distribution $(0.05)(2.18)=3.55$ with a significant level $\alpha=0.05$.

Table 8 also shows that the contribution error of $46.91 \%$ is obtained where this percentage means that all the factors that significantly affect the average value; therefore, it is enough to get involved in the experiment. It is because the Taguchi method requires message contributions to be $\leq 50 \%$ [8].

Table 7. ANOVA average

\begin{tabular}{c|c|c|c|c|c|c}
\hline Source & SS & Df & MS & F ratio & SS & Ratio \% \\
\hline A & 3.127154533 & 2 & 1.563577 & 11.9959 & 2.8665 & 42.22 \\
\hline B & 0,313867531 & 2 & 0.15693 & 1.20400 & 0.05318 & 0.784 \\
\hline C & 0,994034990 & 2 & 0.49701 & 3.81316 & 0.73335 & 10.81 \\
\hline Error & 2.3461705 & 18 & 0.13034 & & 3.12822 & 46.13 \\
\hline SSt & 6.78122758 & 26 & 2.347871 & & 6.78123 & 100 \\
\hline Mean & 67308.607 & 1 & & & & \\
\hline Sstotal & 67301.826 & 27 & & & & \\
\hline
\end{tabular}

Table 8. ANOVA pooling

\begin{tabular}{c|c|c|c|c|c|c|c}
\hline Source & pooled & SS & Df & MS & F ratio & SS & Ratio \% \\
\hline A & Y & 3.1271545 & 2 & 1.56357 & 11.9959 & 2.8665 & 42.22 \\
\hline B & Y & 0,31386753 & & & & & \\
\hline C & Y & 0,99403499 & 2 & 0.49701 & 3.81316 & 0.73335 & 10.81 \\
\hline Error & & 2.3461705 & & & & & \\
\hline pooled & & 2.660038 & 20 & 0,13300 & 1 & 3.18141 & 46.91 \\
\hline SSt & & 6.78122758 & 26 & 0.65572 & & 6.78123 & 100 \\
\hline Mean & & 67308.607 & 1 & & & & \\
\hline SStotal & & 67301.826 & 27 & & & & \\
\hline
\end{tabular}

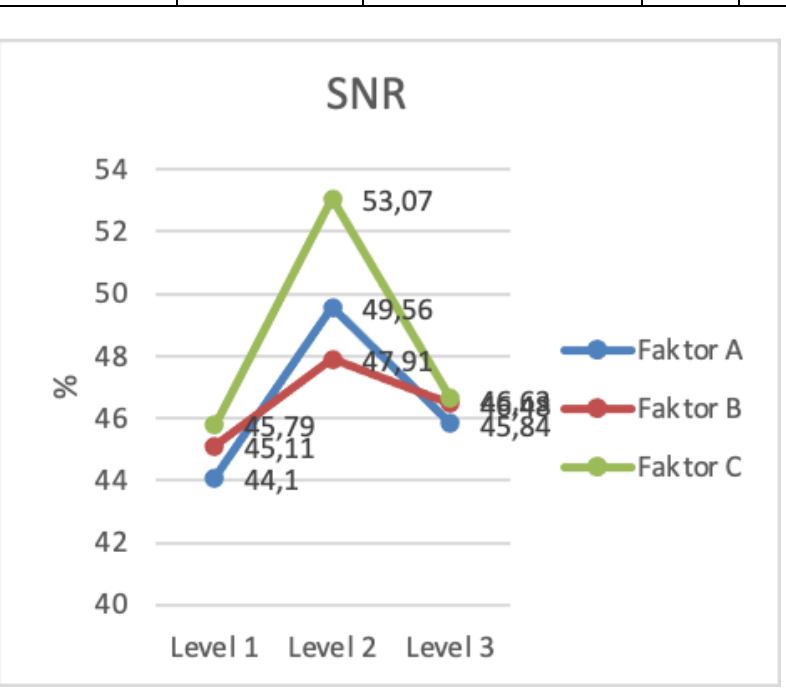

Figure 8. Average porosity graph
From the analysis of experimental results using the Taguchi method, we get a design as the optimal machine setting as in Table 9 .

Table 9. The proposed design of optimal settings

\begin{tabular}{c|c}
\hline Temperature & $210^{\circ} \mathrm{C}$ \\
\hline Printing Speed & $25 \mathrm{~mm} / \mathrm{s}$ \\
\hline Layer Thickness & $0.1 \mathrm{~mm}$ \\
\hline
\end{tabular}

To get the optimal setting based on the largest $\mathrm{S} / \mathrm{N}$ ratio value because, according to the Taguchi concept, the best quality achievement by minimizing the experimental deviation from a target and the highest a $\mathrm{S}$ / $\mathrm{N}$ ratio value means increased robust (tough) noise factor. 


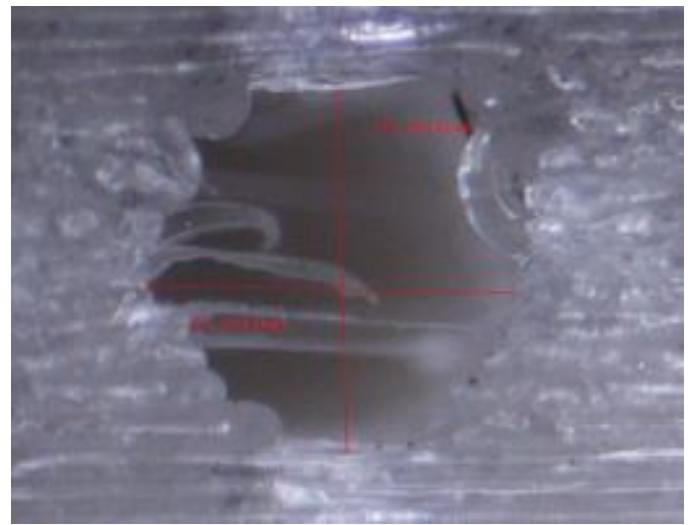

Figure 9. The microscopic view of the fabricated scaffold

Figure 9 shows an artificial and microscopic image. By using microscopic images, the pore sizes were 1253.49 microns and 1253.23 microns. This parameter's mean value is almost the same as the one defined in the 3D printing setting. The amount of scaffold porosity is also measured by the Archimedes principle, which is around $49 \%$.

\section{CONCLUSIONS}

Porosity can be optimized by the Taguchi method. By calculating using analys of variance (ANOVA), the factor that significantly influence porosity quality of the bone scaffold are $42.22 \%$ for nozzle temperature, $10.81 \%$ for layer thickness and $0.78 \%$ for printing speed. Based on the design, the best levels produce $49.93 \%$ porosity and have a high $\mathrm{S} / \mathrm{N}$ ratio using the Taguchi method, namely at $210^{\circ} \mathrm{C}$ nozzle temperature, printing speed $25 \mathrm{~mm} / \mathrm{s}$ and thickness layer $0.1 \mathrm{~mm}$.

\section{ACKNOWLEDGMENTS}

This article's research/publication sponsored from the DIPA of Public Service Agency Sriwijaya University 2020. SP DIPA-023.17.2.677515/2020, revision 01, on March 16, 2020. Under the Rector's Decree Number: 0687/UN9/SK.BUK.KP/2020, on July 15, 2020. We gratefully thank the Mechanical Engineering Department, Faculty of Engineering, Sriwijaya University for their strong support of this study, along with the Medical Device and Technology Center (Meditec), Institute of Human-Centered and Engineering (IHCE), University Technology of Malaysia for their encouragement and many fruitful discussions on this research.

\section{REFERENCES}

[1] M. Hrubovčáková, M. Kupková, and M. Džupon, "Fe and Fe-P Foam for Biodegradable Bone Replacement Material: Morphology, Corrosion Behaviour, and Mechanical Properties," vol. 2016, 2016.

[2] S. Bose, M. Roy, and A. Bandyopadhyay, "Recent Advances in Bone Tissue Engineering Scaffolds," vol. 30, no. 10, pp. 546-554, 2012.

[3] R. A. Giordano, B. M. Wu, W. Scott, L. G. Cima, E. M. Sachs, and M. J. Cima, "Journal of Biomaterials Science, Mechanical Properties of Dense Polylactic Acid Structures Fabricated by Three Dimensional Printing," no. December 2012, pp. 63-75, 1997.

[4] Y. Chen, A. F. T. Mak, M. Wang, J. Li, and M. S. Wong, "PLA Scaffolds with Biomimetic Apatite Coating and Biomimetic Apatite / Collagen Composite Coating to Enhance Osteoblast-like Cells Attachment and Activity," vol. 201, pp. 575580, 2006.

[5] A. P. Valerga, "Influence of PLA Filament Conditions on Characteristics of FDM Parts," 2018.

[6] S. Bose, S. Vahabzadeh, and A. Bandyopadhyay, "Bone Tissue Engineering Using 3D Printing," vol. 16, no. 12, pp. 496-504, 2013.

[7] J. Wang and X. Yu, "Acta Biomaterialia Preparation, Characterization and in vitro Analysis of Novel Structured Nanofibrous Scaffolds for Bone Tissue Engineering," vol. 6, no. 8, pp. 30043012, 2010.

[8] U. Khaleeq, E. Boesch, A. Siadat, M. Rivette, and A. A. Baqai, "Impact of Fused Deposition Modeling ( FDM ) Process Parameters on Strength of Built Parts using Taguchi ' $\mathrm{s}$ Design of Experiments," pp. 1215-1226, 2019.

[9] F. Kabirian, B. Ditkowski, A. Zamanian, R. Heying, and M. Mozafari, "An innovative approach towards 3D-printed scaffolds for the next generation of tissue-engineered vascular grafts," Mater. Today Proc., vol. 5, no. 7, pp. 1558615594, 2018.

[10] R. K. Roy, "Taguchi Method,” 2010. 